\title{
The correlation of distribution of PM number emitted under actual conditions of operation by PC and HDV vehicles
}

\author{
P. Fuc, L. Rymaniak \& A. Ziolkowski \\ Institute of Combustion Engines and Transport, \\ Poznan University of Technology, Poland
}

\begin{abstract}
The paper presents results of tests on particulate matter (PM) in PC and HDV category vehicles fitted with compression ignition engines and various systems of exhaust gas aftertreatment. The measurements were made under actual conditions of use in a city and used portable exhaust gas analyzers belonging to a group of PEMS (Portable Emissions Measurement Systems) - AVL MSS concentration analyzer and TSI EEPS mass spectrometer. The obtained results were processed and coefficients of correlation were determined for PC-PC and PC-HDV. The considerations were made according to Euro 3-5 emission standards. Moreover, the paper discusses a scheme of soot and PM formation as well as describes the influence of exhaust gas aftertreatment systems upon formation of the same.

Keywords: ecology, exhaust emissions, particulate matter.
\end{abstract}

\section{Introduction}

The problem of formation and emission of particulate matter (PM) in internal combustion engines has been addressed for years. Owing to development of measurement devices the structure of PM and conditions favoring their formation may be explored deeper. The mechanism of formation of PM is very complicated and difficult to define unambiguously. It has been assumed that PM is chemical compounds in a liquid or solid state. It is formed in the combustion chamber and has a complex structure including, among others, carbon, sulfur, nitrogen, heavy hydrocarbons and metal particles. Most of the above-mentioned components are hazardous for the human organism and, therefore, manufacturers 
of internal combustion engines introduce various types of systems limiting emissions of the discussed toxic component [1-3]. In the case of vehicles complying with the highest emission standards, there is an additional risk connected with emission of PM characterized by very little size. PM is preserved in the atmosphere for a long time and is easily absorbed in the lungs. Therefore, an attempt should be made to analyses the physical properties of PM on the basis of the total PM number emitted by internal combustion engines complying with various standards and on the basis of tests made under actual conditions of use.

\section{The mechanism of formation of PM}

PM is formed as a result of numerous complex chemical and physical reactions that occur in different places of an internal combustion engine and exhaust system at the same time. One of the most probable mechanisms has been assumed as decomposition of diesel oil into aromatic compounds or acetylene particles. This results in formation of soot, which is the basic element of the structure of PM. The reason for formation of soot in the combustion chamber of compression ignition engines may be:

- locally rich mixture of fuel and air $(\lambda<1)$,

- inappropriate fuel injection parameters,

- too low a combustion temperature,

- cold start of the engine,

and direct reasons include:

- distribution of temperatures in the mixture of fuel and air,

- distribution of concentration of substrates and combustion products,

- kinetics of chemical reactions conditioned upon the volume of oxidizer and local distribution of temperatures,

- values of pressures in the combustion chamber.

In the combustion chamber $\mathrm{CO}$ may decompose, as a result of which pure carbon is formed.

The external structure of soot, dielectric properties and radical character favor absorption of various types of particles. In tests of internal combustion engines $\mathrm{PM}$ is defined as $\mathrm{PM}_{\mathrm{TOTAL}}$, organic or non-organic products that were collected on a filter, through which the stream of diluted exhaust gases flows in the temperature of $52 \pm 3{ }^{\circ} \mathrm{C}$. Among $\mathrm{PM}_{\mathrm{TOTAL}}$ we can distinguish between two basic fractions such as $\mathrm{PM}_{\mathrm{SOF}}$ and $\mathrm{PM}_{\mathrm{INSOL}}$ [4]. The first fraction is a soluble one and the other is insoluble one with carbon with structure resembling graphite as its basic component. $\mathrm{PM}_{\mathrm{INSOL}}$ also includes water bound with sulfates as well as nitrates, metals and other particles containing carbon. Additionally, their structure contains metals originating from abrasion products and particularly hazardous metal particles from catalytic systems, i.e. particles of catalysts. $\mathrm{PM}_{\mathrm{SOF}}$ soluble fraction is composed of hydrocarbons originating from $\mathrm{PM}_{\mathrm{FUEL}}$, formed as a result of combustion of too rich a mixture, process of flame extinguishing and reduction of temperature as a result of decompression. $\mathrm{PM}_{\mathrm{SOF}}$ also contains $\mathrm{PM}_{\mathrm{LUBE}}$ from lube oil. 
The above-mentioned soot formation factors have an indirect or direct influence upon the shape, structure, properties and emission of soot. Application of various technical solutions in modern compression ignition engines relating to composition of diesel oils, power systems as well as modification with the use of various technical agents of the process of combustion of the mixture of fuel and oil would lead to formation of different structures of soot particles (Fig. 1) [5-7]. The types of these structures have a significant influence upon designing of supports and catalytic layers of FCS (Fluorescence Correlation Spectroscopy) and it may affect physical and chemical parameters of soot layers deposited on the wall of a support cell and the process of filter regeneration [8].
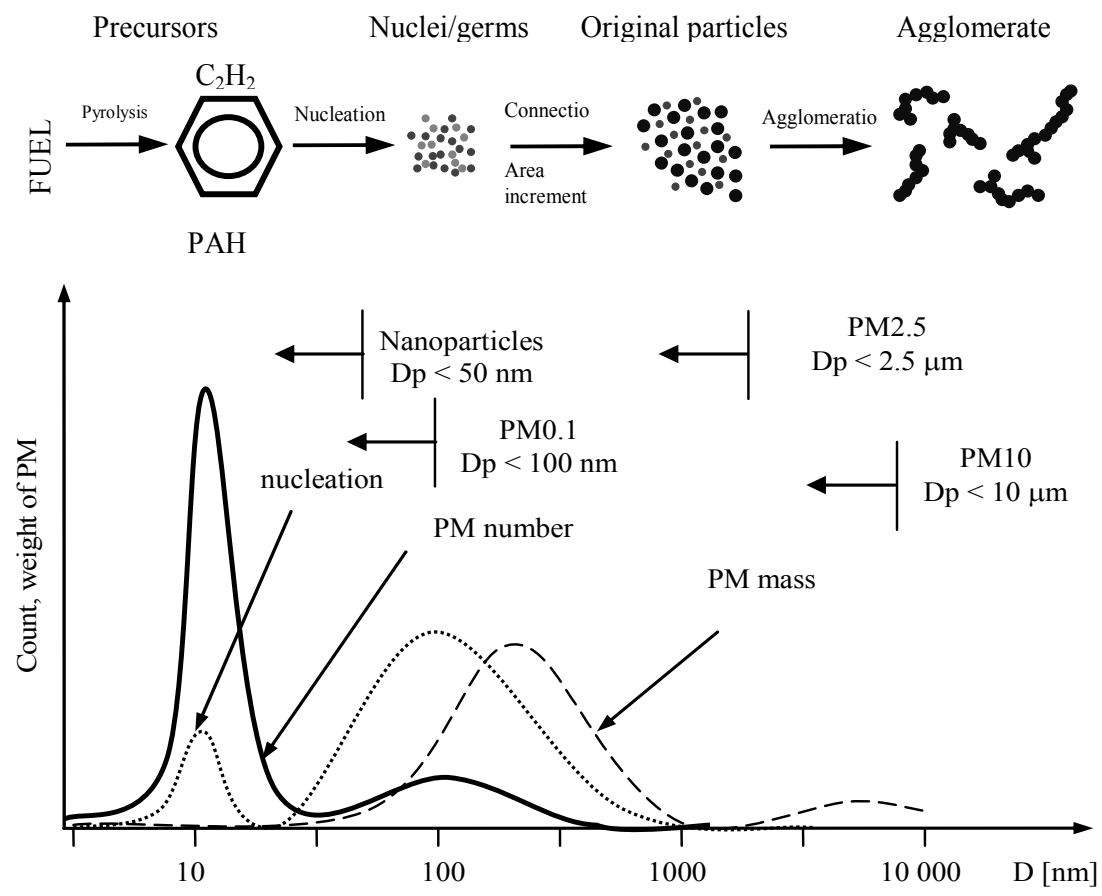

Figure 1: The assumed diagram of soot formation with size distribution of particles $[9,10]$.

The morphology (Greek: morphe $\overline{\mathrm{e}}=$ shape, $\operatorname{logos}=$ science - study of the form and structure) of PM in the context of modern solutions used in internal combustion engines and vehicles should be considered in two aspects. The first aspect relates to most often considered physical parameters, i.e. the size and number. The other aspect relates to chemical parameters such as the structure of a PM and its composition. An important factor from the point of view of an analysis of morphology of PM in the aspect of filtration processes is distribution 
of the number of PM emitted. The distribution differs depending on configuration of the exhaust gas aftertreatment system.

\section{Influence of exhaust gas aftertreatment systems upon formation of PM}

In literature soot emitted from compression ignition engines is analyzed mainly according to the following criteria: engine type (LDD - Light Duty Diesel or HDD - Heavy Duty Diesel), operating parameters of the engine (Fig. 2) and standards of emission of toxic components of exhaust gases complied by the engine $[6,11,12]$. The division of soot according to the last criterion is mainly ascribed to the change of generation of power systems with direct injection of fuel (change of such parameters as injection pressure, droplet size and dose division), optimization of combustion process as well as aftertreatment system (Tab. 1).
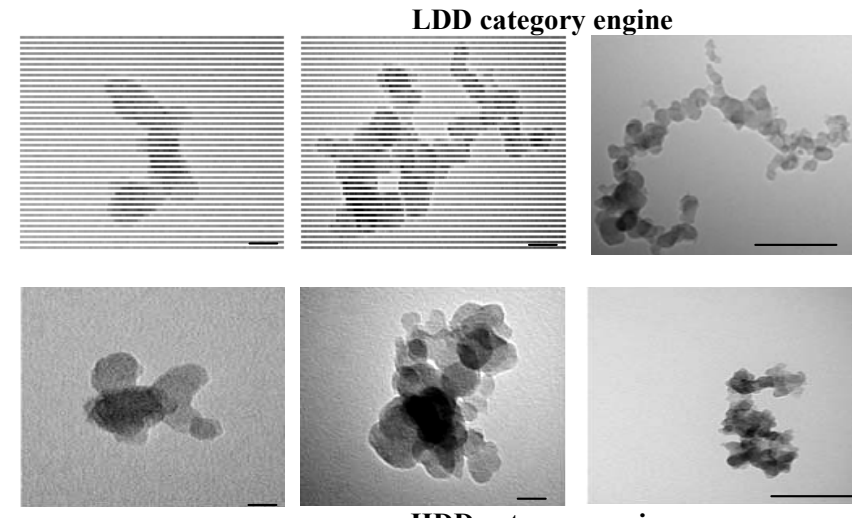

heavy load
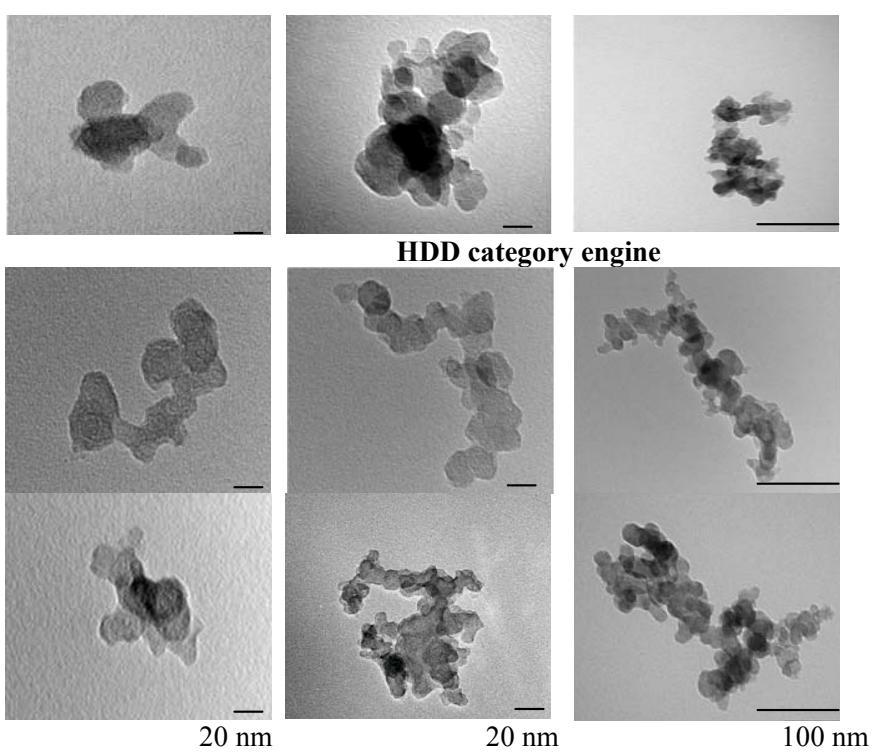

light load

heavy load

light load

Figure 2: Images of various aggregates of soot emitted for various loads of compression ignition engines in PC and HDD category vehicles made with the use of TEM technique [12]. 
Due to the standard complied by the engine, in literature we can distinguish between soot complying with Euro 2-4 [7, 13, 14]. Euro 3 and 4 soot with its morphology and sizes initiating the greatest negative influence upon human health (emission of PM was defined as nanoparticles) is most often considered. Due to considerable similarity to technology of compression ignition engines complying with the limits of Euro 4 and 5 standards (in most cases adjustment of compression ignition engines delivered in Euro 4 technology for compliance with Euro 5 standard was made by the use of DPF - Diesel Particulate Filter) it has been assumed that physical and chemical properties of soot emitted by compression ignition engines complying with Euro 4 and 5 standards are similar.

Table 1: Technologies of exhaust gas aftertreatment systems for PC and HDV categories of vehicles.

\begin{tabular}{|l|l|l|}
\hline \multicolumn{1}{|c|}{$\begin{array}{c}\text { Standard/ } \\
\text { Technology }\end{array}$} & \multicolumn{1}{|c|}{ Pehicle category } \\
\cline { 2 - 3 } Euro 3 & $\begin{array}{l}\text { CR I/PW, EGR+DOC, } \\
\text { optional DPF }\end{array}$ & \multicolumn{1}{c|}{ HDV/non road } \\
\hline Euro 4 & $\begin{array}{l}\text { CR II, EGR+DOC, } \\
\text { optional (DOC }- \text { DPF/CSF) }\end{array}$ & $\begin{array}{l}\text { CR II/PW+EGR/SCR+ } \\
\text { DOC/CRT }\end{array}$ \\
\hline Euro 5 & $\begin{array}{l}\text { CR III, EGR+DOC- } \\
\text { DPF/CSF, optional SCR }\end{array}$ & CR III+EGR/SCR+CRT \\
\hline Euro 6 & $\begin{array}{l}\text { CR IV, } \\
\text { EGR/SCR+DOC-PF/+CSF }\end{array}$ & $\begin{array}{l}\text { CR III+EGR/+SCR+CRT+ } \\
\text { slip NH }\end{array}$ \\
\hline
\end{tabular}

\section{Methodology of tests}

The analysis of morphology of PM requires obtaining of a testing material. Thus, literature considers samples obtained from PC and HDV category engines alternately. There is no information concerning the number of PM obtained for tests from various engines and, therefore, the results were complemented by the author's own tests. The author's own analysis was performed for the full engine set (engine + elements used for emission reduction as selected by manufacturers for compliance with emission limits ascribed to a given vehicle) in order to compare the distribution of the PM number at the tail (Tab. 3). The literature assumes PM for the analysis that is referred to as BS (Black Soot) and originates from synthetic sources (e.g. generators of PM) obtained directly downstream of the exhaust manifold of the engine or from engines fitted with basic exhaust gas aftertreatment systems - exhaust gas recirculation (EGR) and oxidation catalyst (DOC). DOC converters were mostly used as basic systems in vehicles complying with the Euro 3 and 4 standards. PM obtained downstream of the said exhaust gas aftertreatment systems is characterized, upon thermal and chemical processing, by reliable (representative) parameters necessary for further tests connected with their oxidation (afterburning) in DPF. Further technical solutions included the application of DPF, including the in-engine and external solutions that allowed a reduction of emissions necessary for compliance with respective 
legal regulations (particularly Euro 5 standard by PC and HDV vehicles). Comparison of physical parameters of PM emitted by vehicles fitted with DPF was aimed at analysis of the degree of similarity of exhaust gas aftertreatment technologies between the described categories of vehicles.

Tests were made on vehicles that were divided into groups depending on standards of emission complied by the vehicles of a given category (PC, HDV). Adapting engines to new standards of emissions or testing new technologies on vehicles in the market, some manufacturers (often at the level of Euro 3 standard) used modern and almost prototype exhaust gas aftertreatment systems in their vehicles. However, for the purposes of the analysis, we assumed the classification from table 2 without optional equipment.

Table 2: $\quad$ Selected parameters of vehicles used for road tests.

\begin{tabular}{|c|c|c|c|c|c|c|c|}
\hline No. & \multicolumn{3}{|c|}{ PC } & \multirow[b]{2}{*}{ Euro } & \multicolumn{3}{|c|}{ HDV } \\
\hline Vol. & $\begin{array}{c}\text { Vss } \\
{\left[\mathrm{dm}^{3}\right]}\end{array}$ & $\mathrm{Rw}$ & $\begin{array}{l}\text { Aftertreatment } \\
\text { system }\end{array}$ & & Vss & $\mathrm{Rw}$ & $\begin{array}{c}\text { Aftertreatment } \\
\text { system }\end{array}$ \\
\hline 1 & 1.7 & CR I & \multirow{8}{*}{$\mathrm{EGR}+\mathrm{DOC}$} & \multirow{8}{*}{$\begin{array}{l}\text { III } \\
\leftrightarrow\end{array}$} & \multirow{2}{*}{9.2} & \multirow{2}{*}{ PW } & \multirow{2}{*}{ EGR } \\
\hline 2 & 1.9 & PW & & & & & \\
\hline 3 & 1.9 & CR I & & & \multirow{2}{*}{9.2} & \multirow{2}{*}{ PW } & \multirow{2}{*}{ EGR } \\
\hline 4 & 1.9 & CR I & & & & & \\
\hline 5 & 2.0 & CR I & & & \multirow{2}{*}{9.3} & \multirow{2}{*}{ PW } & \multirow{2}{*}{ EGR } \\
\hline 7 & 2.0 & PW & & & & & \\
\hline 8 & 2.0 & PW & & & \multirow{2}{*}{10.5} & \multirow{2}{*}{ CR I } & \multirow{2}{*}{ EGR } \\
\hline 9 & 2.2 & CR I & & & & & \\
\hline 10 & 1.7 & CR II & EGR+DOC & \multirow{5}{*}{$\begin{array}{l}\text { IV } \\
\leftrightarrow\end{array}$} & 7.2 & CR II & $\mathrm{EGR}+\mathrm{DOC}$ \\
\hline 11 & 1.9 & PW & $\mathrm{EGR}+\mathrm{CSF}$ & & 7.2 & CR II & EGR+DOC \\
\hline 12 & 1.9 & CR II & EGR+DOC & & 9.2 & PW & $\begin{array}{c}\text { DOC-DPF } \\
(\mathrm{CRT})+\text { SCR }\end{array}$ \\
\hline 13 & 2.0 & CR II & EGR+DOC & & 9.2 & PW & $\begin{array}{c}\text { DOC-DPF } \\
(\mathrm{CRT})+\mathrm{SCR}\end{array}$ \\
\hline 14 & 2.2 & CR II & EGR+DOC & & 9.2 & PW & $\begin{array}{c}\text { DOC- } \\
\text { DPF+SCR }\end{array}$ \\
\hline 15 & 1.9 & \multirow{5}{*}{ CR III } & $\begin{array}{c}\text { EGR+DOC- } \\
\text { DPF }\end{array}$ & \multirow{5}{*}{$\begin{array}{l}\mathrm{V} \\
\leftrightarrow\end{array}$} & 6,7 & CR III & $\mathrm{SCR}+\mathrm{DPF}$ \\
\hline 16 & 2.0 & & $\mathrm{EGR}+\mathrm{CSF}$ & & 6.7 & CR III & EGR+DPF \\
\hline 17 & 2.0 & & $\begin{array}{c}\text { EGR+DOC- } \\
\text { DPF }\end{array}$ & & 6.9 & CR III & $\begin{array}{c}\text { EGR+DOC- } \\
\text { DPF }\end{array}$ \\
\hline 18 & 2.2 & & $\begin{array}{c}\text { DOC- } \\
\text { DPF+SCR }\end{array}$ & & 9.3 & CR III & EGR \\
\hline 19 & 3.0 & & $\mathrm{EGR}+\mathrm{CSF}$ & & 9.3 & CR III & EGR \\
\hline
\end{tabular}

Table 3: $\quad$ Parameters of routes selected for road tests.

\begin{tabular}{|l|c|c|}
\hline Route parameters & Route 1 & Route 2 \\
\hline Length $[\mathrm{km}]$ & 10,9 & 14 \\
\hline Average speed $[\mathrm{km} / \mathrm{h}]$ & 23 & 25 \\
\hline Average drive time [min.] & 28 & 34 \\
\hline
\end{tabular}


The analysis of the PM number distribution was made on the basis of tests performed under actual conditions of use - in cycles characteristic of urban cycles and in two different testing sections running along streets of the city of Poznań (Fig. 3, Tab. 3).
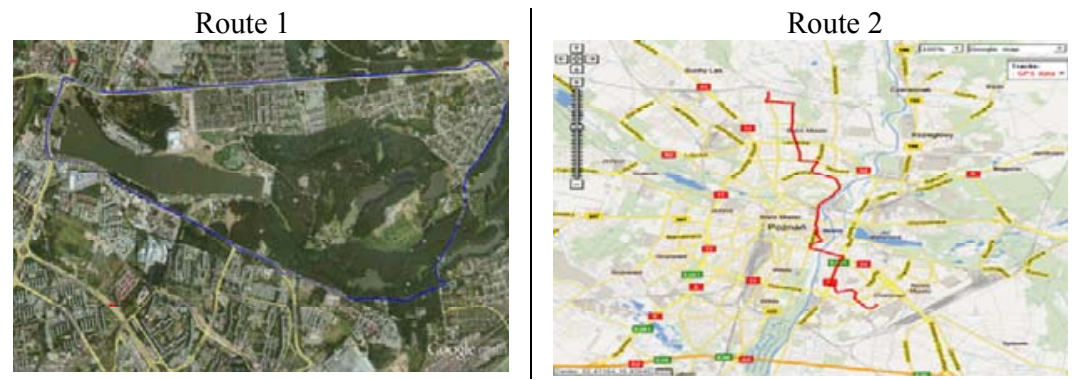

Figure 3: The driving routes during vehicle road tests in urban conditions (created at GPSVisualizer.com).

The concentration of PM in exhaust gases was measured with the use of portable AVL MSS (Micro Soot Sensor) allowing a measurement on a continuous basis. The devices used are characterized by great accuracy and allow measuring of the concentrations from $5 \mu \mathrm{g} / \mathrm{m}^{3}$, which constitutes approx. $10 \%$ of the limit value in emission standards for compression ignition engines. Such a great sensitivity also allows measuring of compression ignition engine parameters. Basic technical data of the analyzer are shown in Table 4.

Table 4: $\quad$ Technical data of portable AVL MSS [15].

\begin{tabular}{|l|l|}
\hline Size of measured particles & $\begin{array}{l}0.005-50 \mathrm{mg} / \mathrm{m}^{3} \text { (non-diluted exhaust gases) } \\
\text { to } 1000 \mathrm{mg} / \mathrm{m}^{3} \text { (with diluted exhaust gases) }\end{array}$ \\
\hline Range index & $1: 10$ \\
\hline Data transmission speed & digital: $\mathrm{do} 5 \mathrm{~Hz}$; analogue: $100 \mathrm{~Hz}$ \\
\hline Exhaust gas sample flow & $\sim 2+2 \mathrm{dm}^{3} / \mathrm{min}$ (total $\sim 4 \mathrm{dm}^{3} / \mathrm{min}$ ) \\
\hline Interfaces & $\mathrm{RS} 232, \mathrm{Digital} \mathrm{I} / \mathrm{O}$, Analog I/O, Ethernet \\
\hline Exhaust gas temperature & to $1000^{\circ} \mathrm{C}$ \\
\hline Indirect pressure of gases & to $2000 \mathrm{mbar}$ \\
\hline Pressure pulsation & $\pm 1000 \mathrm{mbar}$ (max. $50 \%$ of back pressure) \\
\hline Blow volume & $20 \mathrm{dm}^{3} / \mathrm{min}$ at $1000 \mathrm{mbar}$ \\
\hline
\end{tabular}

In order to determine distribution of PM, a portable TSI MODEL 3090 EEPS $^{\mathrm{TM}}$ (Engine Exhaust Particle Sizer ${ }^{\mathrm{TM}}$ Spectrometer) analyzer was used. The analyzer allows continuous measuring of diameters of PM contained in exhaust gases of the engine. Measurements may be recorded with the frequency of up to $10 \mathrm{~Hz}$, which is advantageous during non-stationary engine operation or a cold start. Particle diameters measured fall within the range from 5.6 to $560 \mathrm{~nm}$. Basic technical data of the analyzer is shown in Table 5. 
Table 5: $\quad$ Technical data of a portable TSI 3090 EEPS $^{\text {TM }}$ analyzer [16].

\begin{tabular}{|l|l|}
\hline Size of particles measured & $5.6-560 \mathrm{~nm}$ \\
\hline Number of measurement channels & 16 channels per decade (32 in total) \\
\hline Resolution & 10 sizes of channels/second \\
\hline Flow of exhaust gas sample & $10 \mathrm{dm}^{3} / \mathrm{min}$ \\
\hline Supply of compressed air & $40 \mathrm{dm}^{3} / \mathrm{min}$ \\
\hline
\end{tabular}

\section{The analysis of test results}

Results of tests conducted under actual conditions of use were subject to a detailed analyses and a correlation of values obtained was determined.

a)

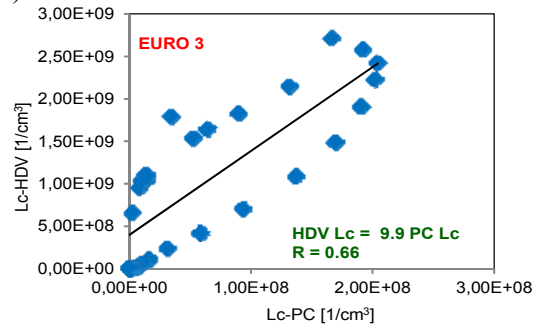

c)

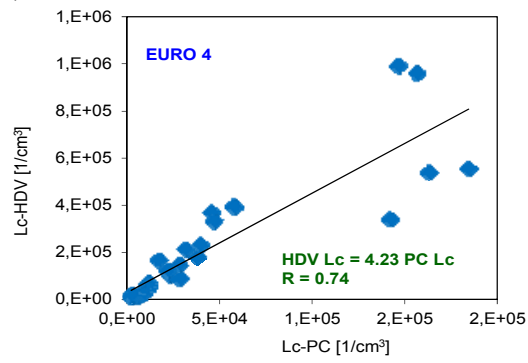

e)

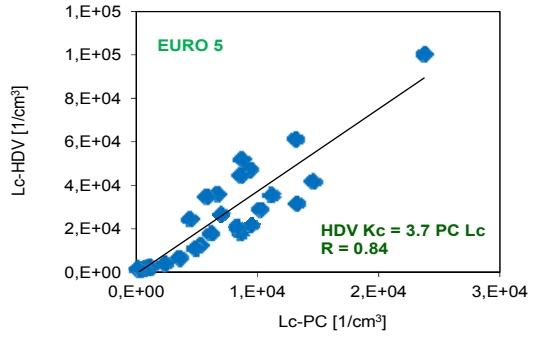

b)

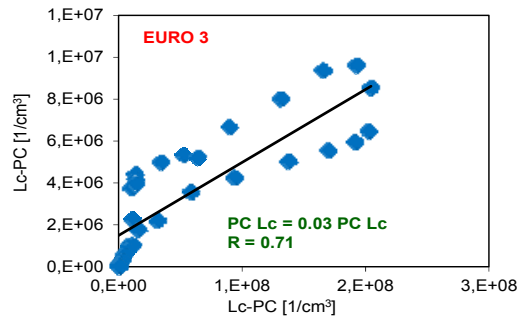

d)

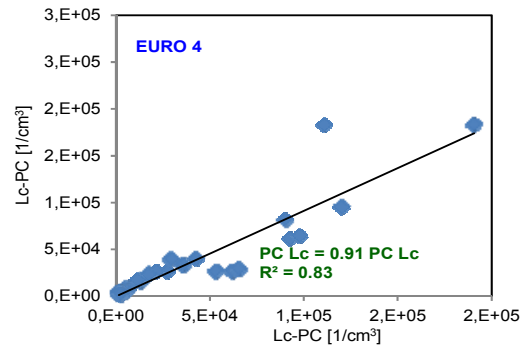

f)

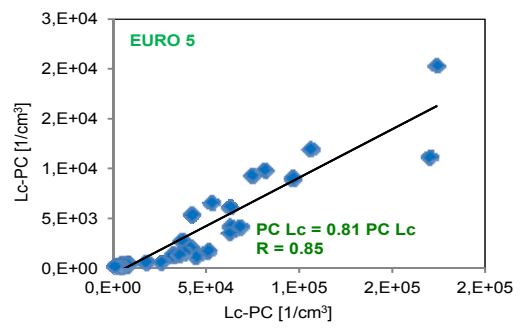

Figure 4: Correlation of concentration of PM measured under actual conditions of use between selected vehicles characterizing LDV and HDV vehicle categories complying with Euro 3-5 emission standards. 
Correlation coefficients constitute an average of the tested vehicles representing each standard. Values of coefficients of the emitted number of PM fall within the range of $\mathrm{R}=0.66-0.85$ (Fig. 4). Table 6 contains a comparison of coefficients of discrepancy determining the share of influence of other systems upon the number of PM emitted by the tested vehicles.

Table 6: Coefficients of discrepancy for PC and HDV category vehicles determining the influence of technology of engines and exhaust gas aftertreatment systems upon concentration and mass of PM.

\begin{tabular}{|c|c|c|c|}
\hline \multirow{2}{*}{} & \multicolumn{3}{|c|}{ For PC category vehicles } \\
\cline { 2 - 4 } & Euro 3 & Euro 4 & Euro 5 \\
\hline $\mathbf{L}_{\mathbf{c}}$ & 0.29 & 0.17 & 0.15 \\
\hline & \multicolumn{3}{|c|}{ For PC and HDV category vehicles } \\
\hline $\mathbf{L}_{\mathbf{c}}$ & 0.34 & 0.26 & 0.16 \\
\hline
\end{tabular}

The obtained results indicate an analogy between the correlation coefficients of the size distribution for Euro 3-5 standards. In the field of technical sciences it has been assumed that a correlation with the coefficient of $\mathrm{R}>0.65$ indicates a clear relation between the tested parameters. For both compared PC-PC and PCHDV vehicles, we obtained the lowest correlation for Euro 3 standard $(\mathrm{R}=0.66$ $0.71)$, average correlation for Euro 4 standard $(R=0.74-0.83)$ and the highest correlation for Euro 5 standard (0.84-0.85). Coefficients of correlation of the PM number for both tested categories of vehicles are characterized by small discrepancies. All vehicles were fitted with high-pressure injection systems of various generations, which, despite considerable differences in maximum injection pressure, lead to a similar, average and symmetrical share of the PM number from each measurement range $(6.4-523 \mathrm{~nm})$. The main reason for this should be seen in the configuration of the injection maps in modern compression ignition engines (engines operating at partial loads as most often is the case in
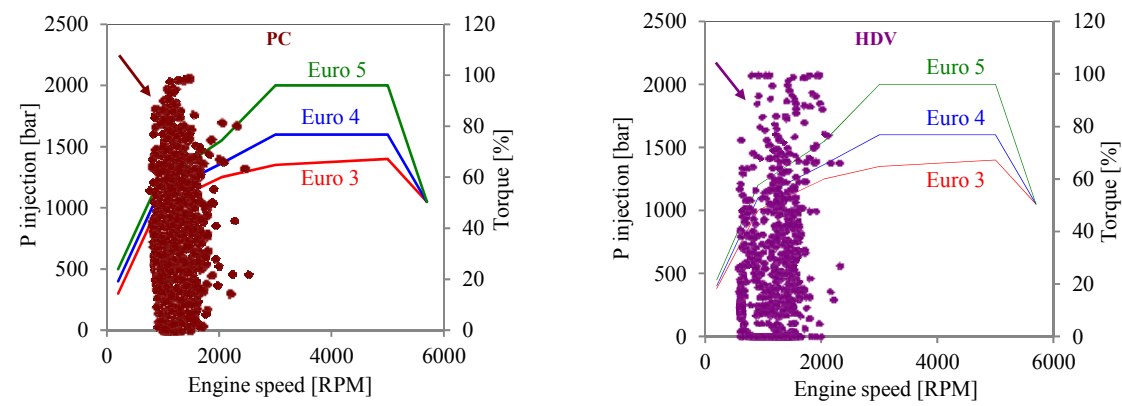

Figure 5: Areas of engine operation in urban traffic for PC and HDV categories of selected tested vehicles depending on injection pressures of injections systems of various generations in accordance with the Euro 3-5 standards. 
urban traffic) for which similar high-pressure injections are obtained (Fig. 5). The maximum injection pressures are obtained for high engine power occurring at high vehicle speeds and loads for mixed traffic and, above all, for highway traffic [17].

When analyzing the coefficients of discrepancy of the PM number between Euro 3 and 5 standards, the authors found 52\% average difference for HDV-PC vehicles and $48 \%$ difference for PC-PC vehicles. Thus, it may be assumed that for both HDV-PC and PC-PC the values are comparable. However, they are different as regards the individual Euro standards. For PC-PC vehicles the differences between Euro 3-4 standards may be assumed as considerable and for PC-HDV vehicles the differences between subsequent standards are similar. This means that for PC vehicles the manufacturers obtained integrated technologies of aftertreatment systems with similar efficiency already at the level of Euro 4 . Differences have been identified as regards particle size from 6.4 to $107 \mathrm{~nm}$.

Comparing HDV-PC vehicles we deal with a different situation. There are discrepancies between individual standards of $45 \%$ on average. This indicates a significant influence of in-engine and external technologies used for Euro 3 to 5 standards on the distribution of PM between PC and HDV vehicles both in the aspect of design of the engines (with a direct influence on the PM morphology) particularly the injection systems and exhaust aftertreatment systems. This applies, in particular, to mutual shifting of the courses of PM number distribution. For Euro 3 standard a visible shift was observed within the entire range of diameters of $\mathrm{PM}$, which is indicated by differences between subsequent points of correlation (Fig. 4a). Comparison of vehicles representing Euro 4 standard indicates a shifting of the size distribution within the range of particles of up to $200 \mathrm{~nm}$. The largest incompliance is found in the size range from 6.4 to $52.3 \mathrm{~nm}$ (Fig. 4b). Considering the Euro 5 standard, the range of differences was shifted from particles with the diameter of up to $220 \mathrm{~nm}$ to particles with the diameter of up to $107 \mathrm{~nm}$. This may indicate a higher effectiveness of the PM mass reduction in the engine exhaust emission and, above all, downstream of the exhaust gas aftertreatment system as well as emission of PM of smaller diameters by PC vehicles.

The conducted analysis indicates that for similar conditions of use of vehicles, there is a correlation between PC-PC and HDV-PC vehicles as regards the size distribution of the emitted PM. Correlation values differ depending on a standard/technology that the tested vehicles comply with. When analyzing the most frequently considered range of PM diameter in literature, i.e. that of 6.04$523.03 \mathrm{~nm}$, greater probability of size distributions for PC-PC vehicles as compared to PC-HDV vehicles was found. The greatest influence on the discrepancies had PM with average diameters of up to $150 \mathrm{~nm}$. A greater share of PM with small diameters was recorded for PC vehicles. This results from a considerably greater number of operation points in urban traffic conditions (Fig. 5). Regardless of the share of engine operation in individual points, the number of operating cycles (share of fuel injections into the combustion chamber with a relative high injection pressure) in engines of $\mathrm{PC}$ vehicles in urban traffic conditions is considerably higher as compared to HDV vehicles. The greater 
number of PM with smaller diameters is not only a result of the stage of nucleation occurring in the engine cylinder during combustion or in a short section of the exhaust system, but it is also a result of partial oxidation of soot in the exhaust gas aftertreatment system during deep regeneration. It should be noted that it leads to a decrease of the mass and not the number of PM. The total PM number emitted for PC vehicles and HDV vehicles is different. A lower PM number are emitted by PC vehicles as compared to HDV vehicles. This results, above all, from parameters of the engine such as displacement, power output and fuel consumed.

\section{Conclusions}

The conducted analysis of correlation of PM number distribution indicates that deliberations relating to the tests connected with the morphology of PM should consider the type of vehicles and specific operating parameters of their engines. In this paper the authors provide a mathematical substantiation for similarity of distributions for PC-PC and PC-HDV vehicles. The obtained test results indicate that the number of PM in exhaust gas is strictly connected with the applied exhaust gas aftertreatment system, including, above all, for solutions fitted with DPF. Obtaining the testing material for tests of morphology of PM plays a significant role as regards the issue of development of appropriate mechanisms of filtration and regeneration depending on exhaust gas aftertreatment systems.

The authors' own methodology makes it possible to conduct comparative tests between technical solutions used in vehicles without the need to use expensive and complicated test systems in chassis dynamometer test conditions. However, it should be considered that a necessary aspect involves testing of the same measurement section. The mileage of a vehicle is less significant. The paper [17] determines a relation between the volumetric index of emission and mileage of a vehicle at the level of $\mathrm{R}=0,91$. The authors also observed that a vehicle load is very significant, which leads to a conclusion that the analysis should be conducted for similar technical parameters used for the testing of vehicles.

\section{References}

[1] Merkisz J., Fuc P.: The Exhaust Emission from Light Duty Vehicles in Road Test in Urban Traffic. SAE Technical Paper Series 2010-01-1558, (2010).

[2] Merkisz J., Pielecha J., Fuc P., Lijewski P., The analysis of the PEMS measurements of the exhaust emissions from city buses using different research procedures. The 8th IEEE Vehicle Power and Propulsion Conference VPPC 2012, Org. KIEE, Paper No. F20120618-0339Seul 912.10.2012, p. 903-907.

[3] Walsh M. P.: Global trends in motor vehicle pollution control; a 2011 update. Part 1. Combustion Engines / Silniki Spalinowe nr 2/2011 (145), p. 106-117, (2011). 
[4] Ignatov O. R., Polivyanchuk A.P.: The analysis of the influence of stabilization conditions of working filters on the sample mass of diesel particulates; a 2012 update. Combustion Engines / Silniki Spalinowe nr 1/2012 (148), p. 48-52, (2012).

[5] Barker J., Richards P., Pinch D., Cheeseman B., Temperature programmed oxidation as a technique for understanding diesel fuel system deposits. SAE Paper 2010-01-1475.

[6] Müller J.O., Su D.S., Jentoft R.E., Kröhnert J., Jentoft F.C., Schlögl R., Morphology-controlled reactivity of carbonaceous materials towards oxidation. Catal. Today 102-103 (2005) 259-265. Department of Inorganic Chemistry, Fritz-Haber-Institute of the MPG, Faradayweg 4-6, 14195 Berlin, Germany.

[7] Su D.S., Jentoft R.E., Müller J.-O., Rothe D., Jacob E., Simpson C.D., Tomović Ž., Müllen K., Messerer A., Pöschl U., Niessner R., Schlögl R., Microstructure and oxidation behavior of Euro IV diesel engine soot: a comparative study with synthetic model soot substances. Catalysis Today 90 (1-2), 2004, p.127-132.

[8] Boehman, A. L., Song, J., and Alam, M. (2005). Impact of biodiesel blending on biodiesel soot and the regeneration of particulate filters. Energy Fuels, 19; 1857-1864.

[9] Iretskaya S., Golden S., Tadrous T., Long S. H., PM control with low $\mathrm{NO}_{2}$ tailpipe emissions by systems with non-PGM catalyzed FCS for passive soot regeneration. SAE Paper 2010-01-0563.

[10] Richter H., Howard J. B., Formation of polycyclic aromatic hydrocarbons and their growth to soot - a review of chemical reaction pathways. Progress in Energy and Combustion Science 26 (2000) 565.

[11] Mooney J. J., Emission control technology for light-duty vehicles. Engelhard Corporation, Asian Vehicle Emission Control Conference AVECC 2001, Jan. 30-Feb 1, 2001 Bangkok, Thailand.

[12] Soewono A., Rogak S., Morphology and raman spectra of engine-emitted particulates. Aerosol Science and Technology, 45:10, 1206-1216, 2011.

[13] Olfert J.S., Symonds J.P.R., Collings N., The effective density and fractal dimension of particles emitted from a light-duty diesel vehicle with a diesel oxidation catalyst. Journal Aerosol Science 38 (2007) s. 69-82.

[14] Su D. S., Microstructure and cytotoxicity of Euro IV and Euro VI diesel engine soot. Talk presented at The $7^{\text {th }}$ Chinese Congress on Environmental Catalysis. Beijing [China]. 2011-08-12 - 2011-08-14.

[15] AVL, Emissions Test Instruments. Micro Soot Sensor. Continuous measurement of soot concentration, Graz 2008.

[16] TSI Inc.: Particle Instruments. Model 3090 Engine Exhaust Particle Sizer ${ }^{\text {TM }}$ Spectrometer, USA 2005.

[17] Pielecha J., Identyfikacja parametrów cząstek stałych z silników spalinowych. Wydawnictwo Politechniki Poznańskiej, 2012. Rozprawy/Politechnika Poznańska; nr 467. 